\title{
The Deterioration of Semantic Networks in Alzheimer's Disease
}

\author{
Israel Martínez-Nicolás ${ }^{1,2} \bullet$ Juan Carro ${ }^{1,2} \bullet$ Thide E. Llorente $^{1,2} \bullet$ \\ Juan José García Meilán ${ }^{1,2}$ \\ ${ }^{1}$ Instituto de Neurociencias de Castilla y León, Universidad de Salamanca, Salamanca, \\ Spain; ${ }^{2}$ Departamento de psicología básica, psicobiología y metodología de las ciencias del \\ comportamiento, Facultad de Psicología, Universidad de Salamanca, Salamanca, Spain
}

Author for correspondence: Israel Martínez-Nicolás, Instituto de Neurociencias de Castilla y León; Facultad de Psicología, Universidad de Salamanca, Spain; Email: israelmani@usal.es Doi: http://dx.doi.org/10.15586/alzheimersdisease.2019.ch11

\begin{abstract}
Language impairments in Alzheimer's disease may appear at the prodromal stage. The most significant impairment is found at the lexical-semantic process level, which is explained either by a degradation of the areas that store the semantic network or by a failure at retrieving the information from that network. Regardless of the retrieval failure happening, there is evidence of the degradation of the semantic network at some levels. Several studies support the bottom-up breakdown, according to which the loss starts at the specific concept attribute level, along with the link with its coordinates, while superordinates are preserved. Some characteristics can affect this loss such as familiarity, age of acquisition, frequency, or affective features. While classic studies have focused on concrete neutral nouns, recent research is exploring the role of emotion. Since emotional processes strengthen the semantic relationship between concepts, it could be a relevant dimension for the preservation of the semantic network.
\end{abstract}

Keywords: conceptual knowledge; concreteness; emotion; language impairments; lexical-semantic access; semantic memory; semantic network

In: Alzheimer's Disease. Thomas Wisniewski (Editor), Codon Publications, Brisbane, Australia. ISBN: 978-0-646-80968-7; Doi: http://dx.doi.org/10.15586/alzheimersdisease.2019

Copyright: The Authors.

License: This open access article is licensed under Creative Commons Attribution 4.0 International (CC BY 4.0). https://creativecommons.org/licenses/by-nc/4.0/ 


\section{INTRODUCTION}

Language impairments appear in most Alzheimer's disease (AD) patients early in the course of the disease, and by the end of it, language becomes completely absent. Although memory impairment is thought to be the first and more evident symptom, an increasing interest in the progression of the deterioration of language throughout the disease shows that language impairments are also present since its prodromal stage (1). An important aspect of language impaired in AD is the ability to access meaning, the representation of knowledge that allows us to understand the world.

Language is strongly based on semantic memory, a storage of concepts linked to linguistic labels. These linkages allow speakers to process the meaning of a linguistic input and to elaborate an appropriate output in response. Language as a cognitive function is sustained by semantic networks, that is, a framework of concepts linked through verbal associations. This network system would be compromised in $\mathrm{AD}$, as the most remarkable impairments in the early stages of $\mathrm{AD}$ are related to the lexical-semantic processes. Such difficulties are most commonly thought to be caused either by a progressive deterioration of the associative structures of a patient's semantic memory, or by a degradation of their content itself (2). In either way, this would cause a loss of concept representation or a severe disorganization of semantic knowledge, which would lead the patients to present with difficulties to find some words and to access to their meaning or attributes, along with a rising number of comprehension errors, and a reduction of the production of semantic features (3). In contrast to that theory, some researches state that the semantic network is preserved, and the difficulties may be due to an impairment in executive processes that causes a failure to retrieve information (4). Consequently, the failure to modulate semantic memory would cause errors and slowness in the search of words.

This chapter intends to summarize the course and characteristics of the semantic deterioration due to Alzheimer's disease and to shed light on the ongoing debate about the underlying impairments. It will start with a brief overview of language impairments, continuing with the course and characteristics of the semantic impairment.

\section{LANGUAGE IMPAIRMENTS IN ALZHEIMER'S DISEASE}

Language suffers several changes throughout the course of AD. First impairment to become evident is anomia and, as a consequence, a deficit in verbal fluency tasks (5). In the mild stages, patients show comprehension as well as production problems, their anomia worsens and their language is characterized by paraphasias, circumlocutions, and lack of content. Verbal production becomes unintelligible when other symptoms such as dysarthria, echolalia, palilalia, and lack of coherence appear in the later stages of the disease. Lastly, the final stage is characterized by mutism and a severe comprehension deficit, thus impeding any kind of social interaction (6).

Lexical-semantic access appears to be first impaired. This process involves searching for a concept in the mind, activating potential phonological candidates and selecting the appropriate one. Thus, the impairments on this regard are 
evidenced by longer response time in lexical decision tasks, and patients face word-finding difficulties along with damage in the semantic processing (7). For this reason, verbal fluency and naming tasks are widely used for cognitive assessment in $\mathrm{AD}$. In verbal fluency tasks, patients must produce as many words as possible in a given time; semantic categories - semantic fluency - or letters - phonemic fluency - may be used as cues. These tasks demand a significant involvement of executive processes, as they require the subject to search for and organize proper responses, monitor their previous ones, and inhibit inappropriate responses. Semantic (SF) and phonemic fluency (PF) differ in the processes involved, and they show divergent declines: while PF relies on lexical representations, SF does so on meaning associations with a superordinate. Moreover, SF tasks in patients with $\mathrm{AD}$ are more impaired than $\mathrm{PF}$ ones (8), which is explained by the distinct involvement of semantic memory. Other tasks affected by the semantic memory breakdown in $\mathrm{AD}$ are naming tests, in which the patients produce semantic paraphasias and, as the disease progresses, an increase in the number of non-response errors, reflecting a pure anomia (9).

In a linguistic level, language production is impaired at early stages, in both written and spoken. Using a description task, Croisile et al. (10) provided evidence of deterioration on both modalities. Overall, written performance was worse than oral, and this effect was found on healthy subjects as well. Regarding the speech of AD patients, they produced shorter responses with fewer information units than healthy older people. Written responses tended to be shorter than oral ones, but they were equally informative. Additionally, it was observed a significant reduction of word categories and an increase of semantic errors in both tasks in AD. Syntax is relatively preserved in the early stages (11), but it worsens through the course of the disease (12). In the beginning, syntax is correct and coherent, but not long afterwards patients start to produce syntactically simplified statements, using fewer subordinate clauses. When maintaining a conversation, AD patients may encounter difficulties responding to open questions and providing new information (13). Most of them are caused by their impairments in comprehension and lexical-semantic access, although damaged verbal pragmatics seems to be also affecting.

In recent years, new techniques of voice and speech analysis have allowed researchers to explore oral production in $\mathrm{AD}$ patients. These studies aim to explore if the changes in language processes have behavioral consequences in the vocal execution. In this regard, speech in $\mathrm{AD}$ is characterized by changes in different temporal and acoustic voice parameters, such as a greater number of voice breaks and hesitations, more pauses when speaking, lower rate of expressive articulation, longer phonation time, and higher mean of the fundamental frequency. All these changes that can be used for early diagnosis of $\operatorname{AD}(14,15)$ are not only due to difficulties in finding the proper word but also caused by some impairments in the processes involved in planning language and how the words relate to each other semantically and syntactically.

\section{SEMANTIC IMPAIRMENTS: PRECLINICAL CHANGES}

Iris Murdoch was a renowned British writer and philosopher. After a prolific career with over 40 published works that had been applauded, critics found her 
last novel, Jackson's Dilemma, to be disappointing. A couple of years later, Murdoch was diagnosed with Alzheimer's disease. Presumably, she had written her last work while the cognitive impairment was already present, in the years leading to the diagnosis. This finding led Garrard et al. (16) to analyze Jackson's Dilemma and two of her other works, written in different periods of her life, in search of early impaired language parameters as a consequence of AD. Among other subtle differences, they noted that content words (nouns, words, and descriptors) had an overall higher mean word frequency in Jackson's Dilemma than in her previous works.

Although it may seem anecdotal, the story of Iris Murdoch is supported by other studies that look for preclinical language markers of the disease by comparing $\mathrm{AD}$, mild cognitive impairment (MCI) and healthy control patients, MCI involves a cognitive decline that it is not explained by normal aging and does not interfere with everyday life. It is expected that about $18 \%$ of the people with MCI will develop $\mathrm{AD}$ (17) and that is the reason why MCI is often considered a preclinical stage of the disease. In a study from Mueller et al. (18), early MCI patients had their speech recorded while describing the "Cookie Theft" picture from the Boston Diagnostic Aphasia Examination. The results showed that there was no decline in syntax and lexical processes; however, an interaction between age and cognitive status was found in semantic and fluency processes, showing a faster decline for patients in a preclinical phase of dementia. Therefore, semantics were affected, producing proportionally less nouns and more pronouns and verbs, which adds evidence to the notion that language may become semantically impoverished early on the continuum of cognitive decline. Another study used this same method to explore potential changes in healthy carriers of the E280A autosomal dominant mutation in the presenilin-1 gene in chromosome 14 , which is related to early onset Alzheimer's disease. These participants did not present clinical symptoms or cognitive problems at the time of the evaluation. Nevertheless, it was found that carriers produced a lower number of semantic units, used simpler sentences, and expressed less semantic information than their non-carriers counterparts, although the number of words employed was similar in both cases. Thus, it can be concluded that a deterioration of the conceptual system is present since the preclinical phase of AD (19). This has been confirmed through classical neuropsychological measures such as the Isaacs test, a semantic verbal fluency task, in which participants show a low performance up to 9 years prior to diagnosis of $\operatorname{AD}(20,21)$.

Given the high rate of progression to $\mathrm{AD}$, it is a current challenge to differentiate those subjects with MCI who will develop AD from those who will not. There is evidence that semantic verbal fluency tasks could be used for that purpose. A study comparing $\mathrm{AD}, \mathrm{MCI}$, and healthy control patients on several language measures found that, while the $\mathrm{AD}$ group showed widespread impairments on traditional semantic memory measures of naming, the MCI group did not differ significantly from controls, except on semantic fluency (22). In longitudinal studies, it has been observed that MCI subjects that will eventually develop AD present with a different pattern in verbal fluency tasks, showing a faster decline in semantic compared to phonemic verbal fluency tasks (23-25). However, these results are not such a promising tool to predict MCI conversion into $\mathrm{AD}$, as $\mathrm{MCI}$ patients' patterns are still very similar to those of healthy controls $(26,27)$. 


\section{CHARACTERISTICS OF THE DETERIORATION OF THE SEMANTIC NETWORK IN AD}

Semantic impairments in AD patients have been well documented through several cognitive tasks. Confrontation naming tasks consist on presenting images of items, animals, or famous person in order for them to provide the target name. As mentioned before, AD patients progress from subtle difficulties to find words to pure anomia. The pattern of errors produced by AD patients in confrontation naming tasks is characterized by a tendency to produce semantic or visuoperceptive errors. Semantic errors usually result from producing the name of the correspondent category instead of that of the target, from mentioning another word from the same category as the target, or from committing circumlocutory errors by giving correct information about the target but not its proper name. As the disease progresses, first type of error become more prevalent, while the opposite occurs to circumlocutory errors. This suggest that less and more inaccurate information is available (28). Overall, this pattern seems to suggest the existence of a disruption in semantic knowledge. However, this might not be the case. Several studies suggest that the pattern is similar for healthy, MCI, and AD groups and that they only differ quantitatively in the number of errors and non-response errors, but not qualitatively. This, added to the fact that AD patients can improve their performance by using phonological clues, suggests that the semantic network might be preserved longer than thought as the information can still be accessed, and the disruption only occurs at later stages, when the non-response errors are more common $(29,30)$.

Another impaired task that gives clues about the state of the semantic associative network is verbal fluency, in which the participant must produce as many words as possible when given a cue. These tasks are widely used for assessing dementia of the Alzheimer's type due to the consistency of the impairment results found $(31,32)$. AD patients produce fewer exemplars per category than healthy controls and tend to produce more general category labels. Although the most common measure is the number of words produced, some other data from this task can be useful to explore the semantic network in AD. For instance, clustering (producing words within subcategories) and switching (shifting between subcategories) are two components that predict performance on verbal fluency tasks. Clustering would be related to the state of the semantic storage with an implication of the temporal lobe, while switching would be related to control, laying on the frontal lobe. According to Troyer et al. (33), AD patients produce smaller clusters than healthy controls, for both semantic and phonemic fluency tasks, but only in the semantic task they show significantly less number of switchings. Therefore, they conclude that the impairment found in fluency tasks is due to an impoverished semantic memory.

The organization of semantic knowledge seems to be compromised as well. In a series of studies using multidimensional scales and pathfinder analysis, Salmon et al. (34) checked the semantic network of AD patients. These techniques can be used to elaborate cognitive maps representing the distant and relationships between concepts by using different semantic tasks measures. In this kind of map, individuals who have never developed a degree of knowledge on an item or who have lost it get a chaotic representation with many unnecessary nodes and that is the case for AD patients. 
For instance, these studies showed how healthy participants tended to produce clearly differentiated clusters of wild and domestic animals, while AD participants tended to mix them. Assuming that verbal fluency represents the activation spreading through the semantic network, this would mean that for $\mathrm{AD}$, that differentiation is not clear and the network is disorganized (35).

Concepts are the basic units of semantic memory. They are constituted by attributes or characteristics and they appear to be structured in a hierarchical way on multiple levels based upon their relationships: super ordinates, coordinates, and subordinates. In $\mathrm{AD}$, these levels of semantic associative relationships show a distinct deterioration. The bottom-up theory states that attributes and coordinates are earlier impaired while the higher level of super ordinates connections remain longer intact. As knowledge of attributes allow individuals to perceive and distinguish an object, the loss of this knowledge would affect different processes such as naming, comprehension, and encoding (36). Semantic priming tasks provide evidence of this theory. When pairing concepts with their attributes, AD patients show a significant slower response time. However, this degradation is not homogeneous as the more salient and significant the attributes are, the longer they are preserved. AD patients are still able to identify the core attributes, that is, those with a higher relative importance for the meaning of the concept $(37,38)$.

On the other hand, semantic priming tasks with pairs of words with a coordinate relationship show the opposite effect. A significant facilitatory effect for coordinate concepts appears in AD patients $(39,40)$. Semantically close concepts are defined by the number of attributes that they share and by those distinctive features that belong to only one of them. For example, both tiger and lion have fur, but only the tiger has stripes. According to this, the semantic priming effect should be related to the overlap of features between the prime and the target. In fact, it has been found that when a pair of words share many attributes and have few distinctive features, the priming effect is larger (41). These results of hyperpriming support the idea that semantic memory is suffering a progressive deterioration that starts with the loss of specific attribute information, and as a consequence, AD patients are no longer capable of distinguishing between two coordinate concepts. Lasney et al. (42) conducted an experiment based on the semantic priming paradigm in which words were paired either by a category coordinate or by an attribute relationship. In addition, they distinguished between close or distant relationships for coordinates, and between shared or distinctive attributes. They found the hyperpriming effect in both close and distant coordinates. On the attributes condition, an impaired priming effect was observed for the distinctive attributes at the beginning of the disease. Only at later stages, shared attributes were affected and showed a weak prime effect. Therefore, as mentioned earlier in the chapter, features shared by many concepts are more resilient to the damage caused by $\mathrm{AD}$, while the distinctive features are more vulnerable. In this sense, the confusion between close concepts that causes the hyperpriming effect would be explained by a loss of distinctive attributes.

\section{DEGRADED NETWORK OR FAILURE TO RETRIEVE?}

Up to this point, we have described the characteristic deterioration of the semantic associative network of $\mathrm{AD}$ patients. Now, the challenge is to explain why 
this happens. There are two possible explanations for the impairments described. The first theory states that the impairment is linked to a breakdown in the organization and structure of the semantic network. The degradation of the neocortical association areas, that are assumed to store the representation of concepts and their attributes, would cause an actual loss of this knowledge. Contrarily, the other theory defends that the cause is a failure to retrieve information from a preserved semantic network, due to impairments in the executive processes involved in accessing such representations (43). While many researchers think that the consistency of semantic impairments through different tasks proves the deterioration of the network, others argue that the fact that $\mathrm{AD}$ patients still can do most of the tasks-although slower than healthy controls—or that they can benefit from phonological cues supports the idea of troubled retrieval mechanisms.

Such controversy has been explored through tasks that imply different cognitive demands. AD patients' distinct performance on phonemic and semantic fluency tasks supports the notion that they may be experiencing a loss or a breakdown in the organization of the semantic memory rather than suffering from difficulties in the retrieval of semantic knowledge. Both phonemic and semantic modalities imply similar executive control demands, and therefore, the main difference is the implication of the semantic memory. This would suggest a degradation of the semantic store $(31,44)$. Rohrer et al. (45) conducted a study asking AD patients to produce words within small categories subsets, and it was found that they produced items faster than controls. This finding could be explained therefore by a loss of associations between concepts within the semantic memory. The degradation of the network would cause a reduction on the potential items that could be activated. Hence, as less items would be available, less time would be needed to reach to them.

The studies by Chan et al. (46) about the organization of semantic network also seem to support the hypothesis of a degraded storage. By analyzing the clusters in verbal fluency tasks, they concluded that $\mathrm{AD}$ patients tend to rely more on the size or other perceptual dimensions rather than on abstract features such as wilderness, compared to healthy controls. The distinct difficulties in accessing words through perceptual or through abstract features seem quite laborious to be explained by the retrieval deficit theory. However, this kind of breakdown can be explained by a disorganized network, the loss of associative relationships and the establishment of new atypical ones.

Errors in naming tasks and their relationship with the integrity of the semantic network has also been explored. There is a relationship between the ability of an $\mathrm{AD}$ patient to name an object and their knowledge of that same object. When they are asked to define an object whose name they cannot access, their descriptions are impoverished, providing less attributes, and even losing core features $(8,47)$.

On the other hand, it has been argued that the impairment found in explicit semantic memory tasks would be caused by the implication of attentional and executive control systems. Therefore, tasks that allow researchers to assess the integrity of the semantic memory while minimizing the influence of those systems can shed light on the matter. That is the case of implicit semantic priming paradigm, which is based on the idea that spreading activation throughout the semantic network requires intact connections within the system. If the network disappears, it should not be possible to prime the target at all. The evidence provided by this task, therefore, strongly supports the retrieval mechanisms 
impairment, since different studies using it consistently found an intact semantic priming in AD patients (48-50). Nevertheless, it seems that this intact network is limited to superordinates, as AD patients show a decline in priming for coordinates and attributes. In this sense, there would be at least a partial disruption in the semantic storage (43).

As can be seen, there is evidence that support both perspectives and therefore there is not a clear conclusion for the debate. One way to address the question would be to demonstrate the complete loss of a concept, which would imply that the person cannot access to the word consistently in different tasks and times, they cannot benefit from semantic cueing and they lose knowledge about the item. Hodges et al. (2) made an attempt to explore that, in which they assessed the semantic memory of AD patients through several tests. They found that when patients were not able to use an item in one task, it was likely to be absent in other task using that same item as a target, thus evidencing a storage degradation. Nonetheless, the aforementioned evidence of an intact semantic network cannot be ignored. Therefore, it seems likely that both impairments occur and have consequences on the performance of AD patients. Neuroimaging seems to support this notion, as an abnormal functioning in the semantic control network and its connections with several areas involved in the semantic processing has been found (51). A conciliatory approach that has been proposed states that, at early stages, the retrieval deficit could be causing the difficulties to which later the degradation is added (52) causing, in the end, a total breakdown.

\section{THE ORGANIZATION OF THE SEMANTIC NETWORK}

There is an intense debate about the existence of amodal or modality-specific domains in the representation of semantic knowledge, with certain deficits providing evidence for both of them. Although it is not the objective of this chapter to discuss the principles by which semantic network is organized, it is noteworthy the amount of research questioning whether it exists category specific deficits or other features that determine that organization. Neurological pathologies with a localized lesion strongly support the notion that separated neural systems process different semantic domains, but the fact that in AD the deterioration affects many cortical regions and patients still seem to show specific domain impairments has created controversy.

It has been commonly reported a differential deficit for living and non-living things in which living things show a better performance (53-55). This difference is usually explained by a sensory-functional view, according to which the semantic representations of living things are identified by sensory properties while nonliving things are so by functional properties. On the other hand, some authors have not found such effect or, having done it, they have attributed it to methodological issues (56-58). Moreover, they argued that the diffuse pattern of deterioration affecting many cortical regions would not justify a differential loss. Furthermore, the fact that some studies find an advantage of non-living things, or no difference at all, may be explained by the election of the tasks or the heterogeneity of the impairments of people with AD. 
There are several factors that could be influencing the categorical deficits, such as word frequency, familiarity, imageability or age of acquisition $(59,60)$. All those variables are related to performance in several language tasks like naming, reading, or priming. Age of acquisition has been studied as a relevant variable due to the possible similarity to the impairment observed in autobiographical memory. That is, the same way that episodic memory for recent events deteriorates faster than for distant memories, concepts acquired later in life could be more easily affected by neural degeneration while early learned words would be more resilient $(61,62)$. In this regard, the patterns of deterioration would mirror the acquisition of semantic associative networks in life-span development.

The role of emotion in the processing of concepts is a fairly unexplored factor. Most studies have been conducted with neutral words. However, some recent studies have focused on the affective information of concepts. Although controversial, the idea of the emotional connotation of words having a role on semantic processes is interesting due to its implications. As emotional processes are relatively preserved in the early stages of $\mathrm{AD}$ compared with other domains, the affective value of concepts could support the preservation of semantic information and, therefore, it could be useful for communication with the patient. In AD patients, the affective information of concepts is longer preserved than other features (63), which would allow AD patients to retain links between close emotional concepts.

Concreteness is another ignored factor. The previous idea leads to the study of concreteness of concepts because there is an interaction between emotional and abstract ones, as the latter usually refer to internal states of the body. In healthy participants, the concreteness effect refers to a faster and more accurate processing of concrete concepts than abstract ones. In $\mathrm{AD}$, as well as in other neurodegenerative diseases, this effect has been noted to suffer a reversal. Giffard et al. (64) conducted a study in which they compared the processing of different concrete and abstract words that could either have a positive, neutral or negative emotional valence. Their result supports the concreteness effect for neutral concepts, while there is no effect for emotional concepts. This suggest that the emotional component of words is the most relevant feature that binds abstract concepts and influences the reversal of the concreteness effect.

\section{CONCLUSION}

Further research on the impairments found in the semantic network of people with $\mathrm{AD}$ is required, as most questions concerning the mechanisms that store and retrieve meaning still have to be solved. For instance, the debate about the underlying processes that cause such impairments remains still open. It seems to be a growing agreement that both deterioration of the network and difficulties in retrieval have a role to some extent. It is noteworthy that in recent years, the discussion has moved from the reason why the semantic network becomes disrupted to how it does it. This is the result of an increasing interest in the way the brain processes meaning and stores semantic information. In this regard, Alzheimer's disease can teach us a lot about the pathological and, by extension, normal functioning of the brain, and contribute to increase the understanding of 
cognitive processes. At the same time, the priority is to help those who suffer from $\mathrm{AD}$ or other neurodegenerative diseases by finding ways to support their abilities and preserve their communication.

Conflict of interest: The authors declare no potential conflicts of interest with respect to research, authorship, and/or publication of this chapter.

Copyright and Permission Statement: To the best of our knowledge, the materials included in this chapter do not violate copyright laws. All original sources have been appropriately acknowledged and/or referenced. Where relevant, appropriate permissions have been obtained from the original copyright holder(s).

\section{REFERENCES}

1. Bastin C, Salmon E. Early neuropsychological detection of Alzheimer's disease. Eur J Clin Nutr. 2014 Nov;68(11):1192-9. http://dx.doi.org/10.1038/ejcn.2014.176

2. Hodges JR, Salmon DP, Butters N. Semantic memory impairment in Alzheimer's disease: Failure of access or degraded knowledge? Neuropsychologia. 1992 Apr;30(4):301-14. http://dx.doi. org/10.1016/0028-3932(92)90104-T

3. Chertkow H, Bub D. Semantic memory loss in dementia of Alzheimer's type. What do various measures measure? Brain J Neurol. 1990 Apr;113(Pt 2):397-417. http://dx.doi.org/10.1093/brain/113.2.397

4. Nebes RD, Martin DC, Horn LC. Sparing of semantic memory in Alzheimer's disease. J Abnorm Psychol. 1984;93(3):321-30. http://dx.doi.org/10.1037/0021-843X.93.3.321

5. Weiner MF, Neubecker KE, Bret ME, Hynan LS. Language in Alzheimer's disease. J Clin Psychiatry. 2008 Aug;69(8):1223-7. http://dx.doi.org/10.4088/JCP.v69n0804

6. Kempler D. Language changes in dementia of the Alzheimer type. Dement Commun. 1995;98-114.

7. Szatloczki G, Hoffmann I, Vincze V, Kalman J, Pakaski M. Speaking in Alzheimer's disease, is that an early sign? Importance of changes in language abilities in Alzheimer's disease. Front Aging Neurosci. 2015;7:195. http://dx.doi.org/10.3389/fnagi.2015.00195

8. Hodges JR, Patterson K, Graham N, Dawson K. Naming and knowing in dementia of Alzheimer's type. Brain Lang. 1996;54(2):302-25. http://dx.doi.org/10.1006/brln.1996.0077

9. Silagi ML, Bertolucci PHF, Ortiz KZ. Naming ability in patients with mild to moderate Alzheimer's disease: What changes occur with the evolution of the disease? Clinics. 2015;70(6):423-8. http:// dx.doi.org/10.6061/clinics/2015(06)07

10. Croisile B, Ska B, Brabant M-J, Duchene A, Lepage Y, Aimard G, et al. Comparative study of oral and written picture description in patients with Alzheimer's disease. Brain Lang. 1996;53(1):1-19. http:// dx.doi.org/10.1006/brln.1996.0033

11. Mueller KD, Koscik RL, Turkstra LS, Riedeman SK, LaRue A, Clark LR, et al. Connected language in late middle-aged adults at risk for Alzheimer's disease. J Alzheimers Dis JAD. 2016 18;54(4):1539-50. http://dx.doi.org/10.3233/JAD-160252

12. Kemper S, LaBarge E, Ferraro FR, Cheung H, Cheung H, Storandt M. On the preservation of syntax in Alzheimer's disease. Evidence from written sentences. Arch Neurol. 1993 Jan;50(1):81-6. http:// dx.doi.org/10.1001/archneur.1993.00540010075021

13. Rousseaux M, Sève A, Vallet M, Pasquier F, Mackowiak-Cordoliani MA. An analysis of communication in conversation in patients with dementia. Neuropsychologia. 2010;48(13):3884-90. http://dx.doi. org/10.1016/j.neuropsychologia.2010.09.026

14. König A, Satt A, Sorin A, Hoory R, Toledo-Ronen O, Derreumaux A, et al. Automatic speech analysis for the assessment of patients with predementia and Alzheimer's disease. Alzheimers Dement Diagn Assess Dis Monit. 2015;1(1):112-24. http://dx.doi.org/10.1016/j.dadm.2014.11.012

15. Martínez-Sánchez F, Meilán JJG, Carro J, Ivanova O. A prototype for the voice analysis diagnosis of Alzheimer's disease. J Alzheimers Dis. 2018;(Preprint):1-9. 
16. Garrard P, Maloney LM, Hodges JR, Patterson K. The effects of very early Alzheimer's disease on the characteristics of writing by a renowned author. Brain J Neurol. 2005 Feb;128(Pt 2):250-60. http:// dx.doi.org/10.1093/brain/awh341

17. Aretouli E, Okonkwo OC, Samek J, Brandt J. The fate of the 0.5s: Predictors of 2-year outcome in mild cognitive impairment. J Int Neuropsychol Soc JINS. 2011 Mar;17(2):277-88. http://dx.doi. org/10.1017/S1355617710001621

18. Mueller KD, Koscik RL, Hermann BP, Johnson SC, Turkstra LS. Declines in connected language are associated with very early mild cognitive impairment: Results from the Wisconsin registry for Alzheimer's prevention. Front Aging Neurosci. 2018;9:437. http://dx.doi.org/10.3389/fnagi.2017.00437

19. Cuetos F, Arango-Lasprilla JC, Uribe C, Valencia C, Lopera F. Linguistic changes in verbal expression: A preclinical marker of Alzheimer's disease. J Int Neuropsychol Soc. 2007;13(3):433-9. http://dx.doi. org/10.1017/S1355617707070609

20. Amieva H, Jacqmin-Gadda H, Orgogozo J-M, Le Carret N, Helmer C, Letenneur L, et al. The 9 year cognitive decline before dementia of the Alzheimer type: A prospective population-based study. Brain. 2005 May 1;128(5):1093-101. http://dx.doi.org/10.1093/brain/awh451

21. Jones S, Laukka EJ, Bäckman L. Differential verbal fluency deficits in the preclinical stages of Alzheimer's disease and vascular dementia. Cortex. 2006 Jan 1;42(3):347-55. http://dx.doi. org/10.1016/S0010-9452(08)70361-7

22. Adlam A-LR, Bozeat S, Arnold R, Watson P, Hodges JR. Semantic knowledge in mild cognitive impairment and mild Alzheimer's disease. Cortex. 2006 Jan 1;42(5):675-84. http://dx.doi.org/10.1016/ S0010-9452(08)70404-0

23. Clark LJ, Gatz M, Zheng L, Chen Y-L, McCleary C, Mack WJ. Longitudinal verbal fluency in normal aging, preclinical, and prevalent Alzheimer's disease. Am J Alzheimers Dis Dementias ${ }^{\circledR}$. 2009;24(6):461-8. http://dx.doi.org/10.1177/1533317509345154

24. Murphy KJ, Rich JB, Troyer AK. Verbal fluency patterns in amnestic mild cognitive impairment are characteristic of Alzheimer's type dementia. J Int Neuropsychol Soc. 2006;12(4):570-4. http://dx.doi. org/10.1017/S1355617706060590

25. Vaughan RM, Coen RF, Kenny R, Lawlor BA. Semantic and phonemic verbal fluency discrepancy in mild cognitive impairment: Potential predictor of progression to Alzheimer's disease. J Am Geriatr Soc. 2018;66(4):755-9. http://dx.doi.org/10.1111/jgs.15294

26. Rinehardt E, Eichstaedt K, Schinka JA, Loewenstein DA, Mattingly M, Fils J, et al. Verbal fluency patterns in mild cognitive impairment and Alzheimer's disease. Dement Geriatr Cogn Disord. 2014;38(1-2):1-9. http://dx.doi.org/10.1159/000355558

27. Teng E, Leone-Friedman J, Lee GJ, Stephanie W, Apostolova LG, Harrell S, et al. Similar verbal fluency patterns in amnestic mild cognitive impairment and Alzheimer's disease. Arch Clin Neuropsychol. 2013;28(5):400-10. http://dx.doi.org/10.1093/arclin/act039

28. Hodges JR, Salmon DP, Butters N. The nature of the naming deficit in Alzheimer's and Huntington's disease. Brain. 1991;114(4):1547-58. http://dx.doi.org/10.1093/brain/114.4.1547

29. Balthazar MLF, Cendes F, Damasceno BP. Semantic error patterns on the Boston Naming Test in normal aging, amnestic mild cognitive impairment, and mild Alzheimer's disease: Is there semantic disruption? Neuropsychology. 2008 Nov;22(6):703-9. http://dx.doi.org/10.1037/a0012919

30. Lin C-Y, Chen T-B, Lin K-N, Yeh Y-C, Chen W-T, Wang K-S, et al. Confrontation naming errors in Alzheimer's disease. Dement Geriatr Cogn Disord. 2014;37(1-2):86-94. http://dx.doi. org/10.1159/000354359

31. Henry JD, Crawford JR, Phillips LH. Verbal fluency performance in dementia of the Alzheimer's type: A meta-analysis. Neuropsychologia. 2004;42(9):1212-22. http://dx.doi.org/10.1016/j. neuropsychologia.2004.02.001

32. Gomez RG, White DA. Using verbal fluency to detect very mild dementia of the Alzheimer type. Arch Clin Neuropsychol. 2006;21(8):771-5. http://dx.doi.org/10.1016/j.acn.2006.06.012

33. Troyer AK, Moscovitch M, Winocur G, Leach L, Freedman M. Clustering and switching on verbal fluency tests in Alzheimer's and Parkinson's disease. J Int Neuropsychol Soc. 1998;4(2):137-43. http:// dx.doi.org/10.1017/S1355617798001374

34. Salmon DP, Butters N, Chan AS. The deterioration of semantic memory in Alzheimer's disease. Can J Exp Psychol Rev Can Psychol Exp. 1999 Mar;53(1):108-17. http://dx.doi.org/10.1037/h0087303 
35. Chan AS, Salmon DP, De La Pena J. Abnormal semantic network for "animals" but not "tools" in patients with Alzheimer's disease. Cortex. 2001 Jan 1;37(2):197-217. http://dx.doi.org/10.1016/ S0010-9452(08)70568-9

36. Cox DM, Bayles KA, Trosset MW. Category and attribute knowledge deterioration in Alzheimer's disease. Brain Lang. 1996;52(3):536-50. http://dx.doi.org/10.1006/brln.1996.0028

37. Nebes RD, Brady CB. Preserved organization of semantic attributes in Alzheimer's disease. Psychol Aging. 1990;5(4):574-9. http://dx.doi.org/10.1037/0882-7974.5.4.574

38. Perri R, Carlesimo GA, Monaco M, Caltagirone C, Zannino GD. The attribute priming effect in patients with Alzheimer's disease. J Neuropsychol. 2019;13(3):485-502. http://dx.doi.org/10.1111/jnp.12168

39. Giffard B, Desgranges B, Nore-Mary F, Lalevée C, Beaunieux H, De La Sayette V, et al. The dynamic time course of semantic memory impairment in Alzheimer's disease: Clues from hyperpriming and hypopriming effects. Brain. 2002;125(9):2044-57. http://dx.doi.org/10.1093/brain/awf209

40. Giffard B, Desgranges B, Nore-Mary F, Lalevée C, De La Sayette V, Pasquier F, et al. The nature of semantic memory deficits in Alzheimer's disease: New insights from hyperpriming effects. Brain. 2001;124(8):1522-32. http://dx.doi.org/10.1093/brain/124.8.1522

41. Perri R, Zannino GD, Caltagirone C, Carlesimo GA. Semantic priming for coordinate distant concepts in Alzheimer's disease patients. Neuropsychologia. 2011 Apr;49(5):839-47. http://dx.doi. org/10.1016/j.neuropsychologia.2011.02.035

42. Laisney M, Giffard B, Belliard S, de la Sayette V, Desgranges B, Eustache F. When the zebra loses its stripes: Semantic priming in early Alzheimer's disease and semantic dementia. Cortex. 2011;47(1): 35-46. http://dx.doi.org/10.1016/j.cortex.2009.11.001

43. Rogers SL, Friedman RB. The underlying mechanisms of semantic memory loss in Alzheimer's disease and semantic dementia. Neuropsychologia. 2008 Jan 15;46(1):12-21. http://dx.doi.org/10.1016/j. neuropsychologia.2007.08.010

44. Haugrud N, Crossley M, Vrbancic M. Clustering and switching strategies during verbal fluency performance differentiate Alzheimer's disease and healthy aging. J Int Neuropsychol Soc. 2011;17(6): 1153-7. http://dx.doi.org/10.1017/S1355617711001196

45. Rohrer D, Wixted JT, Salmon DP, Butters N. Retrieval from semantic memory and its implications for Alzheimer's disease. J Exp Psychol Learn Mem Cogn. 1995 Sep;21(5):1127-39. http://dx.doi. org/10.1037//0278-7393.21.5.1127

46. Chan AS, Butters N, Salmon DP, McGuire KA. Dimensionality and clustering in the semantic network of patients with Alzheimer's disease. Psychol Aging. 1993;8(3):411-19. http://dx.doi. org/10.1037/0882-7974.8.3.411

47. Garrard P, Lambon Ralph MA, Patterson K, Pratt KH, Hodges JR. Semantic feature knowledge and picture naming in dementia of Alzheimer's type: A new approach. Brain Lang. 2005 Apr 1;93(1):79-94. http://dx.doi.org/10.1016/j.bandl.2004.08.003

48. Chertkow H, Bub D, Bergman H, Bruemmer A, Merling A, Rothfleisch J. Increased semantic priming in patients with dementia of the Alzheimer's type. J Clin Exp Neuropsychol. 1994 Aug;16(4):608-22. http://dx.doi.org/10.1080/01688639408402672

49. Nakamura H, Nakanishi M, Hamanaka T, Nakaaki S, Yoshida S. Semantic priming in patients with Alzheimer and semantic dementia. Cortex. 2000;36(2):151-62. http://dx.doi.org/10.1016/ S0010-9452(08)70521-5

50. Bell EE, Chenery HJ, Ingram JCL. Semantic priming in Alzheimer's dementia: Evidence for dissociation of automatic and attentional processes. Brain Lang. 2001;76(2):130-44. http://dx.doi.org/10.1006/ brln.2000.2416

51. Mascali D, DiNuzzo M, Serra L, Mangia S, Maraviglia B, Bozzali M, et al. Disruption of semantic network in mild Alzheimer's disease revealed by resting-state fMRI. Neuroscience. 2018 Feb 10;371: 38-48. http://dx.doi.org/10.1016/j.neuroscience.2017.11.030

52. Salehi M, Reisi M, Ghasisin L. Lexical retrieval or semantic knowledge? Which one causes naming errors in patients with mild and moderate Alzheimer's disease? Dement Geriatr Cogn Disord Extra. 2017 Dec;7(3):419-29. http://dx.doi.org/10.1159/000484137

53. Silveri MC, Daniele A, Giustolisi L, Gainotti G. Dissociation between knowledge of living and nonliving things in dementia of the Alzheimer type. Neurology. 1991;41(4):545. http://dx.doi.org/10.1212/ WNL.41.4.545 
54. Passafiume D, Federicis LSD, Carbone G, Giacomo DD. Loss of semantic associative categories in patients with Alzheimer's disease. Appl Neuropsychol Adult. 2012 Oct 1;19(4):305-11. http://dx.doi. org/10.1080/09084282.2012.670160

55. Peraita H, Díaz C, Anllo-Vento L. Processing of semantic relations in normal aging and Alzheimer's disease. Arch Clin Neuropsychol. 2008 Jan 1;23(1):33-46. http://dx.doi.org/10.1016/j.acn.2007.09.001

56. Laws KR, Gale TM, Leeson VC, Crawford JR. When is category specific in Alzheimer's disease? Cortex. 2005 Jan 1;41(4):452-63. http://dx.doi.org/10.1016/S0010-9452(08)70186-2

57. Moreno-Martínez FJ, Goñi-Imízcoz M, Spitznagel MB. Domain or not domain? That is the question: Longitudinal semantic deterioration in Alzheimer's disease. Brain Cogn. 2011 Oct 1;77(1):89-95. http://dx.doi.org/10.1016/j.bandc.2011.05.006

58. Tippett LJ, Meier SL, Blackwood K, Diaz-Asper C. Category specific deficits in Alzheimer's disease: Fact or artefact? Cortex. 2007 Jan 1;43(7):907-20. http://dx.doi.org/10.1016/S0010-9452(08)70690-7

59. Gainotti G, Di Betta AM, Silveri MC. The production of specific and generic associates of living and nonliving, high- and low-familiarity stimuli in Alzheimer's disease. Brain Lang. 1996 Aug 1; 54(2):262-74. http://dx.doi.org/10.1006/brln.1996.0075

60. Thompson-Schill SL, Gabrieli JDE, Fleischman DA. Effects of structural similarity and name frequency on picture naming in Alzheimer's disease. J Int Neuropsychol Soc. 1999;5(7):659-67. http:// dx.doi.org/10.1017/S1355617799577084

61. Holmes S, Jane Fitch F, Ellis A. Age of acquisition affects object recognition and naming in patients with Alzheimer's disease. J Clin Exp Neuropsychol. 2006;28(6):1010-22. http://dx.doi. org/10.1080/13803390591004392

62. Silveri MC, Cappa A, Mariotti P, Puopolo M. Naming in patients with Alzheimer's disease: Influence of age of acquisition and categorical effects. J Clin Exp Neuropsychol. 2002;24(6):755-64. http://dx.doi. org/10.1076/jcen.24.6.755.8407

63. Giffard B, Laisney M, Eustache F, Desgranges B. Can the emotional connotation of concepts modulate the lexico-semantic deficits in Alzheimer's disease? Neuropsychologia. 2009 Jan 1;47(1):258-67. http://dx.doi.org/10.1016/j.neuropsychologia.2008.07.013

64. Giffard B, Laisney M, Desgranges B, Eustache F. An exploration of the semantic network in Alzheimer's disease: Influence of emotion and concreteness of concepts. Cortex. 2015;69:201-11. http://dx.doi. org/10.1016/j.cortex.2015.05.020 